\title{
Estimasi Standing Stock Sumber Daya Ikan di Danau Toba, Sumatera Utara
}

\author{
Dian Pamularsih Anggraeni, Freddy Supriyadi ${ }^{1}$ \\ *e-mail:nebula_dpa@yahoo.com \\ ${ }^{1}$ Balai Riset Perikanan Perairan Umum dan Penyuluhan Perikanan
}

\begin{abstract}
Lake Toba is the largest lake in Indonesia with an area of 113,000 hectares of water. Lake stock assessment activities carried out to see the current Lake Toba fishery stock. This is necessary as one of the right efforts to maintain the sustainability of fish resources to be maintained, even the production can beimproved. This research estimated the standing stock in Lake Toba by using hydroacoustic method. The tool used is the echosounder BIOSONIC DT-X which is placed as transduser divided bim (split beam echosounder) $200 \mathrm{KHz}$. The calculation results obtained standing stock seen from the density / total fish density in the waters of Lake Toba, which is $40 \mathrm{~kg} /$ ha. When converted to the extent of Lake Toba 113,000 hectares, the standing stock of Lake Toba is 4,520 tons. proportional to the production of fishermen catches of 4,236.56 tons. This value decreased from previous years. Therefore, the management of capture fisheries in Lake Toba, such as the establishment of a conservation zone with good supervision and fish-glass control in order not to become invasive species.
\end{abstract}

Keywords: Toba Lake, density, hidroacoustic, standing stock

\begin{abstract}
ABSTRAK
Danau Toba merupakan danau terbesar di Indonesia dengan luas perairan 113.000 hektar. Kegiatan kajian stok Danau dilakukan untuk melihat stok perikanan Danau Toba saat ini. Hal ini diperlukan sebagai salah satu upaya yang tepat untuk menjaga kelestarian sumber daya ikan supaya dapat dipertahankan, bahkan produksinya dapat ditingkatkan. Penelitian ini dilakukan untuk mengestimasi standing stock di Danau Toba dengan menggunakan metode hidroakustik. Alat yang digunakan adalah echo sounder BIOSONIC DT-X yang ditempatkan sebagai transduser bim terbagi (split beam echosounder) $200 \mathrm{KHz}$. Hasil perhitungan didapatkan standing stock yang dilihat dari densitas/kepadatan ikan total di perairan Danau Toba, yaitu $40 \mathrm{~kg} / \mathrm{ha}$. Apabila dikonversikan dengan luas Danau Toba 113.000 hektar, maka standing stock Danau Toba adalah 4.520 ton, sebanding dengan produksi hasil tangkapan nelayan sebesar 4.236,56 ton. Nilai ini mengalami penurunan dari tahun-tahun sebelumnya. Oleh karena itu, diperlukan pengelolaan perikanan tangkap di Danau Toba, seperti penetapan zona konservasi dengan pengawasan yang baik dan pengendalian ikan kaca-kaca agar tidak menjadi spesies invasif.
\end{abstract}

Kata kunci : Danau Toba, densitas ikan, hidroakustik, standing stock 


\section{PENDAHULUAN}

Danau Toba merupakan danau terbesar di Indonesia dengan luas perairan 113.000 hektar. Menurut wilayah adminitrasi pemerintahan, kawasan Danau Toba dikelilingi tujuh kabupaten, yaitu Kabupaten Tapanuli Utara, Kabupaten Simalungun, Kabupaten Karo, Kabupaten Dairi, Kabupaten Samosir, Kabupaten Toba Samosir, dan Kabupaten Humbang Hasundutan (Silalahi, 2009). Danau Toba memiliki peran multisektoral yaitu antara lain sebagai objek wisata yang sangat dikenal di mancanegara, pembangkit tenaga listrik (PLTA), dan usaha perikanan budidaya sistem keramba jaring apung (KJA) (Ardika, 1999; Lukman, 2013).

Menurut Wijopriono et al (2010), beberapa jenis ikan yang ditemukan di Danau Toba, antara lain ikan batak (Neolissochilus thienemanni) dan (Tor douronensis), hampal (Hampala macrolepidota), mujair (Oreochromis mossambicus), nila (Oreochromis niloticus), gabus (Channa striata), betutu (Oxyeleotris marmorata), lele (Clarias batrachus), mas (Cyprinus carpio), tawes (Barbonymus gonionotus), betok (Anabas testudineus), dan ikan bilih (Mystacoleucus padangensis Bleeker). Salah satu ikan potensi perikanan di Danau Toba bagi masyarakat adalah ikan pora-pora yang sebenarnya adalah ikan bilih, hasil introduksi dari Danau Singkarak. Ikan bilih sebelum diintroduksi di Danau Toba adalah ikan endemik yang hidup di Danau Singkarak, Sumatera Barat. Kemampuannya tumbuh berkembang di Danau Toba menyebabkan ikan bilih tidak lagi dimasukkan ke dalam kategori ikan endemik. Tahun 2003 ikan bilih dari Danau Singkarak diintroduksi ke Danau Toba sebanyak 2.840 ekor (Kartamihardja \& Sarnita, 2010). Introduksi ikan bilih tersebut dinilai berhasil berkembang dengan baik di Danau Toba dibandingkan dengan habitat aslinya di Danau
Singkarak. Ikan bilih di Danau Toba mengalami peningkatan dalam populasi. Kegiatan penangkapan ikan bilih cukup membantu perekonomian masyarakat di sekitar Danau Toba. Kartamihardja et al, (2012) mengemukakan bahwa sejak tahun 2003 perikanan tangkap di Danau Toba didominasi oleh ikan bilih. Hasil tangkapan ikan bilih sejak tahun 2004 terus meningkat dan puncaknya terjadi pada tahun 2012 dengan hasil tangkapan tertinggi mencapai 45.000 ton, yang sebagian besar merupakan hasil tangkapan alat tangkap bagan. Saat ini sudah tidak ditemukan lagi ikan bilih di Danau Toba. Menurut Suryanti (2015), pada penelitiannya tahun 2014 nilai rata-rata laju eksploitasi ikan bilih di Danau Toba telah melebihi nilai laju eksploitasi optimum $(0,5)$ sehingga menunjukkan adanya overfishing pada ikan bilih. Produksi tangkapan nelayan ikan bilih per alat tangkap yang semakin menurun juga menjadi indikasi adanya overfishing, meskipun tidak menutup kemungkinan penurunan produksi tangkapan nelayan ikan bilih disebabkan oleh faktor lain yang diduga munculnya ikan kaca-kaca sebagai spesies baru di Danau Toba.

Menurut Rengi et al (2013), selama ini kegiatan pemanfaatan sumber daya ikan melalui kegiatan penangkapan mempunyai kecenderungan semakin tidak terkendali, dimana jumlah tangkap tidak lagi seimbang dengan daya pulihnya. Oleh karena itu dilakukan kajian standing stock ikan untuk mengetahui potensi perikanan tangkap di Danau Toba saat ini dan untuk mengetahui kondisi populasi ikan. Hasil penelitian juga diharapkan dapat menunjang ketahanan pangan masyarakat yang tinggal di sekitar perairan. Hal ini diperlukan sebagai salah satu upaya yang tepat untuk pengelolaan sumberdaya perikanan Danau Toba agar kelestariannya dapat dipertahankan. 


\section{METODE}

Pengelolaan sumber daya perikanan yang baik harus mengontrol jumlah hasil tangkapan dalam hubungannya dengan jumlah stok ikan yang dapat dieksploitasi. Untuk itu diperlukan suatu perkiraan jumlah stok ikan pada saat itu dan teknik survei dalam memperkirakan kelimpahan ikan pada waktu dan kondisi tertentu. Penelitian ini menggunakan metode hidroakustik untuk mengestimasi standing stock. Metode hidroakustik memiliki kemampuan menganalisis distribusi kelimpahan kumpulan dengan jangkauan jarak kedalaman yang luas terhadap suatu organisme yang tidak merusak lingkungan dan menggambarkan kondisi saat itu juga. Danau Toba merupakan danau yang luas dan memiliki kedalaman yang tinggi, sehingga digunakan metode ini untuk menduga besarnya stok ikan. Metode ini memanfaatkan gelombang suara yang merambat pada medium air untuk pendeteksian bawah air (underwater), memungkinkan memperoleh data secara real time, akurat, dan berkecepatan tinggi sehingga dapat memberikan kontribusi yang cukup tinggi bagi penyediaan data dan informasi sumberdaya perikanan (Maclennan \& Simmonds, 1992).

Penelitian survei dilakukan di wilayah perairan Danau Toba pada bulan Februari Desember 2017. Secara geografik Danau Toba terletak pada koordinat $2^{\circ} 10^{\prime} \mathrm{LU}-3^{\circ} 0^{\prime} \mathrm{LU}$ dan $98^{\circ} 20^{\prime}$ BT - 99 $59^{\circ}$ ' BT. Kepadatan stok ikan di Perairan Danau Toba ditentukan dengan metode hidroakustik menggunakan alat echosounder BIOSONIC DT-X yang ditempatkan di atas kapal dengan penempatan transduser bim terbagi (split beam echosounder) $200 \mathrm{KHz}$ pada sisi luar kapal. Penelitian survei ini diakukan dengan tracking mengelilingi Danau Toba mulai dari Kabupaten Samosir sampai Kabupaten Karo. Luas perairan Danau Toba yang disurvey untuk pengamatan akustik kurang lebih $302 \mathrm{mil}^{2}$.
Data produksi hasil tangkapan juga diperoleh dari wawancara dengan nelayan dan data yang dikumpulkan oleh enumerator. Enumerator mengumpulkan data hasil tangkapan nelayan selama Bulan Februari Desember 2017.

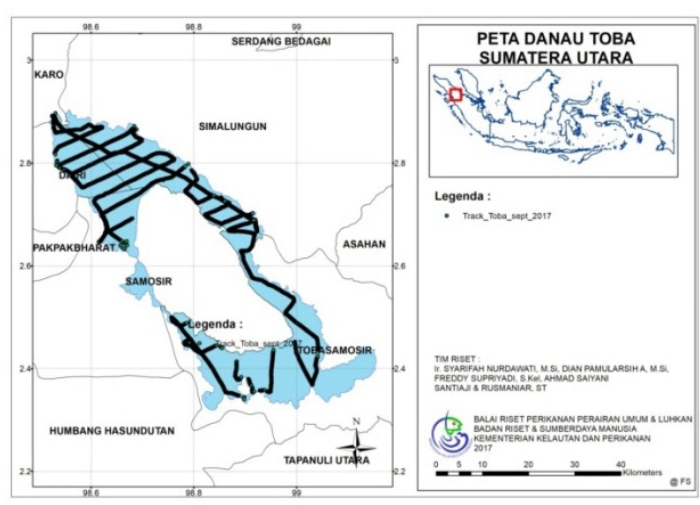

Gambar 1. Track pengambilan data akustik di Perairan Danau Toba Sumatera Utara, September 2017

\section{Pengolahan Data Akustik}

\section{Target Strength}

Target strength (TS) merupakan kemampuan dari suatu target untuk memantulkan suara yang mengenainya. Target strength ditetapkan pada ambang minimum -80 $\mathrm{dB}$, namun target yang diolah dalam analisis selanjutnya dikelompokkan menjadi kelompok ikan kecil (TS dari -69 sampai -60 dB, setara dengan panjang ikan $<5 \mathrm{~cm}$ TL), ikan sedang (TS dari -57 sampai -45 dB, setara dengan panjang ikan 5-18 cm TL), dan ikan besar (TS dari -42 sampai $-33 \mathrm{~dB}$, setara dengan panjang ikan 20-70 cm TL) berdasarkan kekuatan target panjang hubungan empiris yang disarankan oleh Love (1977) dalam Wijopriono et al (2010). Nilai target strength menunjukkan bahwa semakin besar nilai TS identik dengan ukuran ikan yang lebih besar, sedangkan semakin kecil nilai TS identik dengan ukuran ikan yang lebih kecil. Konversi nilai target strength menjadi ukuran panjang (L) untuk ikan pelagis digunakan persamaan (Hannachi et al, 2004) :

$$
\mathrm{TS}=20 \log \mathrm{L}-73,97
$$


Menurut Hile (1936) dalam Effendie (2002), hubungan panjang (L) dan bobot (W) dari suatu spesies ikan yaitu :

$$
\mathrm{W}=\mathrm{a} \mathrm{L}
$$

\section{Densitas Ikan (Kelimpahan Ikan)}

Estimasi stok ikan didapatkan dengan menganalisis nilai densitas ikan dilakukan pada Microsoft Excel. Pengolahan dapat dilakukan setelah proses integrasi SV dan TS. Densitas dihasilkan dengan menggunakan formula (Iida et al., 1996 dalam Lubis, 2015) :

$\mathrm{SV}(\mathrm{dB})=10 \log (\mathrm{N} \tau \mathrm{bs})$

$$
=10 \log \mathrm{N}+\mathrm{TS}
$$

Dengan asumsi kepadatan numerik adalah sebanding dengan kepadatan individu, maka persamaan di atas dapat ditulis kembali sebagai berikut:

$$
\mathrm{SV}(\mathrm{dB})=10 \log \rho+\mathrm{A}
$$

Dimana :

$$
\mathrm{SV}=\text { volume strength }(\mathrm{dB})
$$

$\rho=$ kelimpahan $/$ densitas organisme (ind $/ \mathrm{m}^{3}$ )

$\mathrm{A}=$ target strength rata-rata $(\mathrm{dB})$

Tabel 1. Komposisi Nilai Target Strength menurut Strata Kedalaman Perairan

\begin{tabular}{cccc}
\hline $\begin{array}{c}\text { Strata } \\
\text { Kedalaman }\end{array}$ & $\mathbf{- 6 6} \mathbf{s} / \boldsymbol{d} \mathbf{- 6 0}$ & Target Strength (dB) & $\mathbf{- 4 4} \mathbf{s} / \mathbf{d} \mathbf{- 3 6}$ \\
\hline $1-25 \mathrm{~m}$ & 2 & $\mathbf{- 5 9} \mathbf{s} \mathbf{d} \mathbf{- 4 5}$ & 4 \\
$26-50 \mathrm{~m}$ & 8 & 95 & 37 \\
$51-75 \mathrm{~m}$ & 4 & 25 & 66 \\
$76-100 \mathrm{~m}$ & 11 & 20 & 72 \\
$101-125 \mathrm{~m}$ & 14 & 18 & 63 \\
$126-150 \mathrm{~m}$ & 39 & 24 & 41 \\
$151-175 \mathrm{~m}$ & 37 & 46 & 18 \\
$176-200 \mathrm{~m}$ & 0 & 92 & 6 \\
\hline
\end{tabular}

\section{HASIL DAN PEMBAHASAN}

\section{Target Strength}

Hasil pada tabel 1 menunjukkan bahwa target dengan nilai TS dari -66 sampai $-60 \mathrm{~dB}$ merupakan ikan dengan ukuran kecil. Perolehan sampel yang dikumpulkan menunjukkan dugaan bahwa pada interval ini adalah ikan kaca-kaca (Parambassis siamensis). Ukuran ikan kaca-kaca yang diperoleh berkisar antara $4-6,5 \mathrm{~cm}$ (Gambar 2a dan 2b). Ikan ini masih terdeteksi pada kedalaman sampai 151-175 m.
Hasil juga menunjukkan ikan-ikan yang lebih besar dengan interval TS dari -59 sampai $-45 \mathrm{~dB}$ yaitu setara dengan panjang ikan $5-18$ $\mathrm{cm}$. Pada interval ini, ikan yang terdeteksi banyak berada pada stratifikasi kedalaman 1 $50 \mathrm{~m}$. Ikan kaca-kaca yang berukuran $>5 \mathrm{~cm}$ dapat masuk juga dalam interval ini. Hasil tangkapan lain yang ada dalam kisaran TS ini diperkirakan juga ikan nila dan lobster. Menurut Ahmad (2010), TS ikan nila berkisar antara -44,77 sampai dengan -32,15 dB. Panjang lobster yang tertangkap berkisar antara 5,5 - $16 \mathrm{~cm}$. Ikan nila dan lobster 
merupakan hasil tangkapan yang mendominasi hasil tangkapan di perairan Danau Toba.

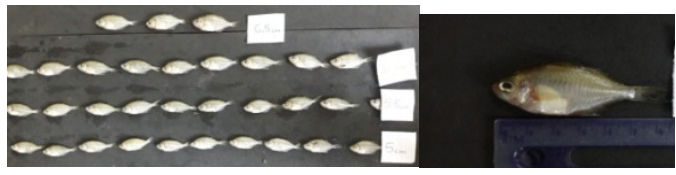

(a)

(b)

Gambar 2a. Sampel ikan kaca-kaca dengan ukuran

$5-6,5 \mathrm{~cm}$

2b. Ikan kaca-kaca dengan ukuran $6,5 \mathrm{~cm}$

Ikan-ikan besar dengan ukuran $>20 \mathrm{~cm}$ memiliki target strength berkisar -44 sampai $36 \mathrm{~dB}$. Pada interval ini, ikan yang terdeteksi banyak berada pada stratifikasi kedalaman 51 - $125 \mathrm{~m}$. Ikan yang terdeteksi ini kemungkinan adalah ikan mas dan ikan nila. Perkiraan jenis ikan ini mengacu pada penelitian yang dilakukan Ahmad (2010). Menurut Ahmad (2010), TS ikan mas berkisar antara $-39,1$ sampai dengan $-32,2 \mathrm{~dB}$.

Hasil pada tabel 1 juga menunjukkan bahwa target yang terdeteksi pada kedalaman 176-200 $\mathrm{m}$ berjumlah kecil dikarenakan sedikitnya sampling pada perairan dengan kedalaman ini. Pada kedalaman ini terdeteksi ikan-ikan yang memiliki TS berkisar -59 sampai -43 dB. Secara umum ikan-ikan dengan ukuran yang lebih besar lebih banyak terdeteksi pada kedalaman yang lebih dalam. Hal ini sesuai dengan perbedaan swimming layer dari masing-masing ukuran ikan. Ikan dengan ukuran lebih besar cenderung berenang di perairan dalam dibandingkan ikan berukuran kecil.

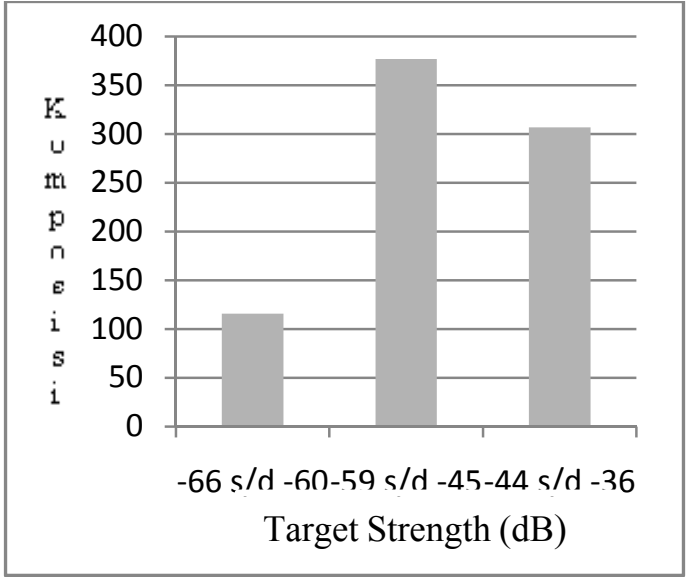

Gambar 3. Komposisi sesuai Kelompok Target Strength

Hasil pengolahan data akustik menunjukkan bahwa ikan yang banyak terdeteksi pada kisaran nilai target strength (TS) -59 sampai - $45 \mathrm{~dB}$, pada area pengamatan seluas $302 \mathrm{mil}^{2}$. Jenis ikan-ikannya diperkirakan adalah ikan nila, ikan mas, dan lobster (Gambar 3).

\section{Densitas Ikan (Kelimpahan Ikan)}

Densitas atau kelimpahan ikan merupakan nilai kepadatan ikan di kolom perairan yang digunakan untuk menetapkan standing stock di perairan. Nilai komposisi dari masing - masing target pada tiap strata digunakan dalam penentuan komposisi berat untuk mendapatkan nilai biomassa ikan perairan Danau Toba. Tabel 2 menunjukkan bahwa densitas rata-rata tertinggi terdapat pada strata kedalaman 1- 25 m yaitu 10,8767 ekor/1000 $\mathrm{m}^{3}$, didominasi ikan-ikan berukuran sedang yang kemungkinan adalah ikan mas, ikan nila, dan lobster. Rata-rata terkecil adalah pada strata kedalaman 176 - $200 \mathrm{~m}$, yaitu 0,0048 ekor/ $1000 \mathrm{~m}^{3}$, dengan rata-rata 1,7596 ekor/1000 $\mathrm{m}^{3}$ (Tabel 2). 
Tabel 2. Rata-rata Densitas Absolut pada tiap Strata Kedalaman

\begin{tabular}{cc}
\hline $\begin{array}{c}\text { Strata } \\
\text { Kedalaman }\end{array}$ & $\begin{array}{c}\text { Volume Density } \\
\left(\text { ekor } / \mathbf{1 0 0 0} \mathbf{~ m}^{\mathbf{3}}\right)\end{array}$ \\
$\mathbf{1}-\mathbf{2 5} \mathbf{~ m}$ & $\mathbf{1 0 , 8 7 6 7}$ \\
$\mathbf{2 6}-\mathbf{5 0} \mathbf{~ m}$ & $\mathbf{1 , 0 1 0 6}$ \\
$51-75 \mathrm{~m}$ & 0,2799 \\
$76-100 \mathrm{~m}$ & 0,1058 \\
$101-125 \mathrm{~m}$ & 0,0220 \\
$126-150 \mathrm{~m}$ & 0,0116 \\
$151-175 \mathrm{~m}$ & 0,0109 \\
$176-200 \mathrm{~m}$ & 0,0048 \\
\hline
\end{tabular}

Luas perairan Danau Toba yang disurvey untuk pengamatan akustik kurang lebih 302 $\mathrm{mil}^{2}$. Luas perairan inilah yang dipakai sebagai acuan dalam penentuan volume perairan untuk menentukan densitas ikan di perairan, sehingga didapatkan nilai densitas total 40 $\mathrm{kg} / \mathrm{ha}$. Potensi sumberdaya perikanan pada strata 1-25 $\mathrm{m}$ dan 26-50 $\mathrm{m}$ cukup besar, nilainya $35,307 \mathrm{~kg} / \mathrm{ha}$ dan $3,246 \mathrm{~kg} / \mathrm{ha}$ untuk luas perairan Danau Toba yang disurvey. Luas area Danau Toba 113.000 hektar, sehingga didapatkan standing stock saat survey adalah 4.520 ton. Data yang didapatkan dari enumerator juga menunjukkan bahwa produksi hasil tangkapan rata-rata nelayan per tahunnya $1.059,14 \mathrm{~kg} /$ tahun, dimana jumlah nelayan Danau Toba secara keseluruhan 4.000 Rumah Tangga Perikanan (RTP), sehingga diperoleh produksi hasil tangkapan di Danau Toba 4.236,56 ton. Estimasi jumlah stok ikan di perairan Danau Toba menggunakan metode hidroakustik dengan menganalisis data kepadatan ikan sebagai acuannya memberikan nilai yang cukup akurat. Nilai ini sebanding dengan data produksi hasil tangkapan yang diperoleh dari enumerator. Nilai standing stock ini menunjukkan penurunan jika dibandingkan dengan penelitian Wijopriono et al (2010) yang berkisar antara $4.226-6.762$ ton/ha per tahun. Hal ini mungkin disebabkan terjadinya overfishing pada saat ikan melimpah. Ikan yang dalam kondisi yang mau memijahpun tertangkap, sehingga ikan tidak dapat berproduksi dan berkembang. Diketahui saat ini sudah sulit ditemukan ikan bilih (Mystacoleucus padangensis) yang populasinya cukup melimpah setelah introducing. Pengambilan sampel ikan di Danau Toba juga sudah tidak didapatkan ikan bilih. Data yang diperoleh dari enumerator menyatakan bahwa tidak ditemukan lagi ikan bilih sebagai hasil tangkapan nelayan. Hal ini sesuai dengan penelitian yang dilakukan Suryanti (2015) bahwa menurunnya produksi ikan bilih mengindikasikan adanya overfishing, walaupun tidak menutup kemungkinan penurunan produksi tangkapan nelayan ikan bilih disebabkan oleh faktor lain yang diduga munculnya ikan kaca-kaca di Danau Toba.

Menurut Hedianto et al (2015), menurunnya produksi ikan bilih ini juga diduga karena kehadiran ikan kaca-kaca di Danau Toba, yang dianggap sebagai predator. Ikan kaca yang aktif makan di malam hari (nokturnal) memakan telur ikan bilih yang terapung di permukaan.

Data enumerator pada tahun 2017 menunjukkan bahwa hasil tangkapan yang mendominasi ketika survey dilakukan adalah ikan nila dan lobster. Di perairan Danau Toba juga banyak terdapat ikan kaca-kaca (Parambassis siamensis), tetapi nelayan di Danau Toba tidak menangkap ikan kaca-kaca sebagai hasil tangkapannya karena dianggap tidak memiliki nilai ekonomis.

Hasil penelitian ini menunjukkan bahwa sumber daya ikan di Danau Toba sudah menurun. Walaupun tergolong pada sumber daya perikanan yang dapat diperbaharui 
(renewable resources), tetapi bila pemanfaatannya tidak terkendali akan mengakibatkan hasil tangkapan yang semakin berkurang. Standing stock di Danau Toba yang menurun dari tahun sebelumnya menunjukkan bahwa stok ikan tidak boleh dimanfaatkan secara berlebihan. Oleh karena itu, diperlukan pengelolaan perikanan tangkap di Danau Toba, seperti penetapan zona konservasi dengan pengawasan yang baik dan pengendalian ikan kaca-kaca agar tidak menjadi spesies invasif.

\section{KESIMPULAN}

Nilai standing stock Danau Toba yang mengalami penurunan menunjukkan bahwa sudah terjadi over fishing atau penangkapan yang berlebihan. Oleh karena itu, diperlukan pengelolaan untuk menunjang keberlangsungan perikanan tangkap di Danau Toba, terutama pada strata kedalaman 1-25 m dan 26-50 m karena potensi perikanan Danau Toba pada kedua strata tersebut cukup besar. Kajian-kajian terhadap dinamika populasi, produksi, dan habitat ikan potensi di Danau Toba perlu dilakukan untuk menetapkan langkah-langkah pengelolaan sumber daya perikanan tangkap seperti penetapan zona konservasi dengan pengawasan yang baik, dan pengendalian ikan kaca-kaca agar tidak menjadi spesies invasif.

\section{Ucapan Terima Kasih}

Tulisan ini merupakan bagian dari kegiatan penelitian "Estimasi Stok KPP PUD 439 - Danau Toba", Tahun Anggaran 2017 di Balai Riset Perikanan Perairan Umum dan Penyuluhan Perikanan. Terima kasih disampaikan kepada Ir. Syarifah Nurdawati, M.Si. dan seluruh pihak yang telah mendukung terhadap pelaksanaan penelitian, terutama pada para enumerator.

\section{DAFTAR PUSTAKA}

\section{Jurnal Ilmiah :}

Ginting, Desty W., Pujiono Wahyu Purnomo, dan Abdul Ghofar. 2013. Potensi dan Pengelolaan Sumberdaya Ikan Pora-pora (Mystacoleucus padangensis Bleeker) di Danau Toba Sumatera Utara. Diponegoro Journal of Maquares Vol.2 No.4 Tahun 2013, Halaman $28-37$.

Harianja, Dedy, Muhammad Ridha Syafii Damanik, dan Restu. 2018. Kajian Tingkat Pencemaran Air di Kawasan Perairan Danau Toba Desa Silima Lombu Kecamatan Onanrunggu Kabupaten Samosir. Jurnal Geografi Vol.10 No.2 $(176-183)$

Koeshendrajana, S. 2011. Kebijakan dan Strategi Pengelolaan Perikanan Tangkap di Danau Toba Pasca Introduksi Ikan Bilih. Jurnal Kebijakan Perikanan Indonesia 3(1):1-12.

Tjahjo, Didik Wahyu Hendro, et.al. 1998. Potensi Sumber Daya Perikanan di Danau Toba, Sumatera Utara. Jurnal Penelitian Perikanan Indonesia Vol.IV No.1 Tahun 1998.

Wijopriono, K. Purnomo, E. S. Kartamihardja, and Z. Fahmi. 2010. "Fishery Resources and Ecology of Toba Lake". Inland Fishery Resources Journal. Vol. 16 No. 1 June 2010: 7-14.

\section{Prosiding :}

Ardika. G. 1999. "Danau dan Waduk dalam pengembangan pariwisata berkelanjutan (Lake and Reservoir in the Development of Continuable Tourism System)". Prosiding Semiloka Nasional Pengelolaan dan Pemanfaatan Danau dan waduk, PPLH- IPB. Ditjen Bangda - Depdagri. Ditjen Pengairan-Dep. PU, 
dan Kantor Men-LH. Bogor. hlm. IV (113).

Hedianto, D. A. Dan Endi Setiadi Kartamihardja. 2015. "Karakteristik Biologi dan Dampak Introduksi Ikan Kaca (Parambassis siamensis, Fowler 1973) di Danau Toba". Prosiding Forum Nasional Pemulihan dan Konservasi Sumberdaya Ikan - V.

Kartamihardja, E. S. dan K. Purnomo. 2006. "Keberhasilan introduksi ikan bilih (Mystacoleucus padangensis) ke habitatnya yang baru di Danau Toba, Sumatera Utara". Prosiding. Seminar Nasional Ikan IV. Jatiluhur, Purwakarta. 9 p.

\section{Buku :}

Arnaya, I. N. 1991. Diktat Kuliah Dasar Dasar Akustik. Institut Pertanian Bogor. Bogor. 84 hal.

Effendie, M. I. 2002. "Biologi Perikanan". Yayasan Pustaka Nusatama. 163 pp.

Gulland, J.A., 1983. "Fish stock assessment". A manual of basic methods. John Wiley and Sons.

Hannachi, M. S., L. B. Abdallah, and O. Marrakchi. 2004. "Acoustic Identification of Small Pelagic Fish Species : Target Strength Analysis and School Descriptor Classification". MedSudMed Technical Documents No.5.

Kartamihardja, E.S. Sarnita AS. 2010. "Populasi Ikan Bilih di Danau Toba : Keberhasilan Introduksi Ikan dan Implikasi Pengelolaan dan Prospek Masa Depan”. Pusat Riset Perikanan Tangkap, Badan Riset Kelautan dan Perikanan, Departemen Kelautan dan Perikanan. 50p.

Lukman. 2013. Danau Toba. "Karakteristik
Limnologis dan Mitigasi Ancaman Lingkungan dari Pengembangan Karamba Jaring Apung”. LIPI.

MacLennan, D.N and Simmonds. 1992. "Fisheries Acoustic". Chapman and Hall.London. 325 p.

Panjaitan. p. 2010. "Kajian bio-ekologi populasi ikan bilih di perairan Danau Toba". VISI No 18 (2): 354 - 261.

Rengi, P., Hamdan Alawi, dan Sumarto. 2013. "Kajian Stok Ikan Selais (Cryptopterus spp.) di Perairan Umum Kabupaten Kuantan Singingi". Berkala Perikanan Terubuk, Juli 2013, hlm 40 - 57 Vol. 41. No.2 ISSN 0126 - 4265.

\section{Skripsi, Tesis, Disertasi :}

Ahmad, Faisal. 2010. "Pengukuran Target Strength Beberapa Spesies Ikan dalan Kondisi Terkontrol di Laboratorium Akustik Kelautan Menggunakan Quantified Fish Finder". Fakultas Perikanan dan Ilmu Kelautan. Institut Pertanian Bogor.

Lubis, M. Z. 2015. "Aplikasi Split Beam Akustik untuk Deteksi Single Target dan Scatttering Volume dalam Pendugaan Densitas Ikan di Bidang Perikanan". Sekolah Pasca Sarjana Program Studi Teknologi Kelautan IPB.

Silalahi, Juliana. 2009. Analisis Kualitas Air dan Hubungannya dengan Keanekaragaman Vegetasi Akuatik di Perairan Balige Danau Toba. Sekolah Pascasarjana Universitas Sumatera Utara.

Suryanti, Ani. 2015. "Tesis Ekobiologi Ikan Bilih Mystacoleucus padangensis (Bleeker, 1852) sebagai Dasar Pengelolaan di Sungai Naborsahan, Danau Toba, Sumatera Utara". Sekolah Pascasarjana IPB. 


\section{Laporan :}

Kaban, Siswanta, Arif Wibowo, Abdul Karim Gaffar, dan Mirna Dwirastina. 2013. Laporan Teknis : Karakteristik Potensi Sumber Daya Ikan Bilih dan Kesinambungan Pengelolaan Perikanan di Danau Toba, Sumatera Utara. Balai Penelitian Perikanan Perairan Umum.

Kartamihardja, E. S., C. Umar, E. Prianto, Y. Priatno dan S. Koeshendrajana. 2012. "Penerapan model optimasi produksi sumberdaya ikan bilih melalui penerapan kawasan konservasi di Danau Toba, Sumatera Utara". Laporan IPTEKMAS. Puslit Pengelolaan Perikanan dan Konservasi Sumberdaya Ikan, Badan Litbang Kelautan dan Perikanan, KKP. $75 \mathrm{p}$.

Oakley, Josh. 2014. Modelling The Aquaculture Carrying Capacity of Lake Toba, Northg Sumatra, Indonesia. A Major Paper Submitted in Partial Fullfillment of The Requirements for The Degree of Master of Environmental Science and Management. University of Rhode Island. 